\title{
The effects of hydrogen sulfide under sevoflurane administration against ischemia and reperfusion injury in isolated rat heart
}

\author{
Dong Kyu Lee, Sang Ho Lim, and Nan Suk Kim \\ Department of Anesthesiology and Pain Medicine, Korea University Guro Hospital, Seoul, Korea
}

Background: Hydrogen sulfide $\left(\mathrm{H}_{2} \mathrm{~S}\right)$ produces a protective effect against myocardial ischemia and reperfusion injury. Sevoflurane, which is used for anesthesia in cardiac problem patients, also has a protective effect. This study is designed to reveal the effects of $\mathrm{H}_{2} \mathrm{~S}$ under sevoflurane using rat hearts.

Methods: The hearts were Langendorff-perfused, subjected to 30 minutes ischemia and 60 minutes reperfusion. Group I was a control group. The other groups were pretreated for 15 minutes before ischemia as follows: $1.6 \%$ sevoflurane for group S; $18.5 \mu \mathrm{M} \mathrm{H}_{2} \mathrm{~S}$ S for group $\mathrm{H}$; and $1.6 \%$ sevoflurane and $18.5 \mu \mathrm{M} \mathrm{H}_{2} \mathrm{~S}$ simultaneously for group HS. Hemodynamics and the infarct size were measured.

Results: Group HS presented depressed hemodynamics during pretreatment. LV function in group HS achieved better recovery than group I after reperfusion. The infarct size of groups S, H and HS was smaller than group I, while there were no differences between groups $\mathrm{S}, \mathrm{H}$ and $\mathrm{HS}$.

Conclusions: Exogenous $\mathrm{H}_{2} \mathrm{~S}$ did not enhance the preconditioning effects of sevoflurane. Rather, the results suggest that $\mathrm{H}_{2} \mathrm{~S}$ under sevoflurane might depress hemodynamics. (Korean J Anesthesiol 2012; 62: 461-467)

Key Words: Heart, Hydrogen sulfide, In vitro, Ischemia, Reperfusion injury, Sevoflurane.

\section{Introduction}

In administering anesthetics to high cardiac risk patients for surgery, the primary purpose is to maintain a cardiac reservoir. Of the many attempts to achieve this during anesthesia, a great deal of attention has been paid to the powerful defense mechanism, ischemic preconditioning that results from short repetitive myocardial ischemia. However, since there are difficulties in utilizing ischemic preconditioning during surgery $[1,2]$, considerable research has been undertaken in the pursuit of a pharmacological solution with effects that are similar to ischemic preconditioning. Several substances, including halogenated inhalation anesthetics, have been found to cause such pharmacological preconditioning [3]. Sevoflurane is a halogenated inhalation anesthetic which has a pharmacological preconditioning effect and so is often used as a general anesthetic

Received: October 24, 2011. Revised: 1st, November 8, 2011; 2nd, December 6, 2011; 3rd, December 8, 2011. Accepted: December 9, 2011. Corresponding author: Nan Suk Kim, M.D., Ph.D., Department of Anesthesiology and Pain Medicine, Korea University Guro Hospital, Guro 2-dong, Guro-gu, Seoul 152-703, Korea. Tel: 82-2-2626-1437, Fax: 82-2-851-9897, E-mail: nskim@korea.ac.kr

(c) This is an open-access article distributed under the terms of the Creative Commons Attribution Non-Commercial License (http:// creativecommons.org/licenses/by-nc/3.0/), which permits unrestricted non-commercial use, distribution, and reproduction in any medium, provided the original work is properly cited. 
for patients with cardiac diseases [4].

Hydrogen sulfide $\left(\mathrm{H}_{2} \mathrm{~S}\right)$ is thought to be a gasotransmitter that is naturally produced in small amounts in the human body such as nitric oxide (NO) and carbon monoxide (CO) and has many biological functions [5]. $\mathrm{H}_{2} \mathrm{~S}$ is synthesized from L-cysteine through the action of cystathionine $\gamma$-lyase in the myocardium, fibroblasts and the vascular smooth muscles, and is well distributed throughout the cardiovascular system. $\mathrm{H}_{2} \mathrm{~S}$ reduces the contractility of the myocardium and acts as a vasodilator leading to the dilation of vascular smooth muscles [6]. Several animal-based studies have shown that externally administered $\mathrm{H}_{2} \mathrm{~S}$ has the same effect as natural $\mathrm{H}_{2} \mathrm{~S}$ in reducing damage from myocardial ischemia and reperfusions [7-12]. Its myocardial protective effects are regarded as similar to that of ischemic preconditioning; $\mathrm{H}_{2} \mathrm{~S}$ has a unique action in vertebrates called 'suspended animation-like state' [13]. That is, $\mathrm{H}_{2} \mathrm{~S}$ induces extremely low metabolism and low oxygen consumption status such as deep hypothermia, and can protect vital organs including the heart against ischemia and reperfusion injury [13-16].

It is thought that if $\mathrm{H}_{2} \mathrm{~S}$ is administrated along with sevoflurane, it can provide another effect against myocardial damage from ischemia occurring due to surgery or the course of the disease, subsequently leading to the reduction of post-operative myocardial dysfunction in high-risk patients. However, $\mathrm{H}_{2} \mathrm{~S}$ is not yet in clinical use because its mechanisms, pharmacological actions and interactions with other medications are not fully understood. Therefore, this study was conducted to examine the effects of $\mathrm{H}_{2} \mathrm{~S}$ on isolated rat hearts that were treated with sevoflurane and to analyze what effects the $\mathrm{H}_{2} \mathrm{~S}$ would exert on the myocardium.

\section{Materials and Methods}

The study protocol was approved and all procedures were performed in accordance with the guidelines recommended by the Institutional Animal Care and Use Committees.

Our study utilized an isolated rat heart model on a Langendorff system (Radnoti Co., Colorado Springs, Colorado, USA). The hearts were taken from 52 male Spraque-Dawley white rats weighing between $250-350 \mathrm{~g}$, and were divided into 4 groups by using a block randomization.

Phenobarbital $100 \mathrm{mg} / \mathrm{kg}$ was injected into the abdominal cavity of each rat and the cessation of voluntary movement was ascertained. Once the rat was completely anesthetized, 1,000 IU heparin was injected into the abdominal cavity. Before spontaneous respiration ceased, a tracheotomy was performed and a 16-G catheter was inserted and attached to an animal respirator (SN-480-7, Shinano Co., Nagano, Japan). Mechanical ventilation was initiated at 50 breaths $/ \mathrm{min}$, with
3-4 ml tidal volume using 95\% oxygen-5\% carbon dioxide. The sternum was incised and the heart was exposed. The heart was then extracted and immediately placed in iced perfusate to stop movement and prevent damage to the myocardium. The Langendorff system's perfusate cannula was inserted into the aorta of the isolated heart, with the tip positioned immediately above the aortic valve through which the perfusate was entered into the coronary artery. The perfusate used was a modified Kreb's solution ( $\mathrm{NaCl} 118.0 \mathrm{mM}, \mathrm{KCl} 4.7 \mathrm{mM}, \mathrm{CaCl}_{2} 1.9 \mathrm{mM}$, $\mathrm{MgSO}_{4} 1.2 \mathrm{mM}, \mathrm{NaHCO}_{3} 25.0 \mathrm{mM}, \mathrm{KH}_{2} \mathrm{PO}_{4} 1.2 \mathrm{mM}$, Glucose $10.1 \mathrm{mM}$, Na-EDTA $0.5 \mathrm{mM}$ ). The perfusate was maintained at $37 \pm 0.2^{\circ} \mathrm{C}$ using a heated circulator with an automated temperature control (CW-10G, Jeio Tech Co. Seoul, Korea) and entered the Langendorff system's oxygenator through a perfusate pump (Masterflex, Cole-Parmer Instrument Co., USA). The perfusate's height was maintained at $75 \mathrm{~cm}$, and the pressure of the perfusate entering the coronary artery was maintained at $55 \mathrm{mmHg}$. The perfusate's $\mathrm{pH}$ was maintained at $7.4 \pm 0.02$ by setting the oxygenator at $95 \%$ oxygen- $5 \%$ carbon dioxide at $3 \mathrm{~L} / \mathrm{min}$. In order to continuously measure hemodynamic parameters, a latex balloon filled with saline was inserted through the left mitral valve into the left ventricle, and a stainless steel conduit was used to connect a pressure sensor (Ohmeda P23XL transducer, Ohmeda, Oxnard, CA, USA) to an MP-100 system (Biopac ${ }^{\circledR}$ system Inc., CA, USA) and an MP100 manager program, Acknowledge version 3.8.2 (Biopac ${ }^{\circledR}$ system Inc., CA, USA). The other cannula was introduced through the coronary sinus via the right atrium for measuring the coronary effluent rates. Then, after stabilization, the balloon was controlled to obtain a left ventricular end diastolic pressure of around $10 \mathrm{mmHg}$ before observation.

All hearts in the 4 groups were maintained on the Langendorff system, allowed to stabilize, given the initial treatment for 15 minutes, underwent artificially induced global ischemia for 30 minutes, and then underwent reperfusion for 60 minutes. Initial treatment in group I (ischemia) was simply to maintain coronary flow. Group S (sevoflurane) hearts were treated with sevoflurane at 1.6 vol\% through the oxygenator using a Sevotec 5 vaporizer (Datex-Ohmeda, Tewksbury, MA, USA), group H $\left(\mathrm{H}_{2} \mathrm{~S}\right)$ hearts were treated with the perfusate containing $100 \mu \mathrm{M}$ sodium hydrosulfide corresponding to $18.5 \mu \mathrm{M} \mathrm{H}_{2} \mathrm{~S}$ and group $\mathrm{HS}\left(\mathrm{H}_{2} \mathrm{~S}\right.$ and sevoflurane) hearts were treated with the perfusate containing $18.5 \mu \mathrm{M} \mathrm{H}_{2} \mathrm{~S}$ as well as with 1.6 vol\% sevoflurane during the pre-treatment period (Fig. 1). Measurements for statistical analysis were taken directly after stabilization and after pre-treatment as well as 5, 30 and 60 minutes after initiation of reperfusion. Variables recorded for analysis were the left ventricular end systolic pressure (LVESP), left ventricular end diastolic pressure (LVEDP), maximum difference of ventricular pressure $\left(\mathrm{dP} / \mathrm{dt}_{\max }\right)$ and heart rate $(\mathrm{HR})$, as well as coronary 


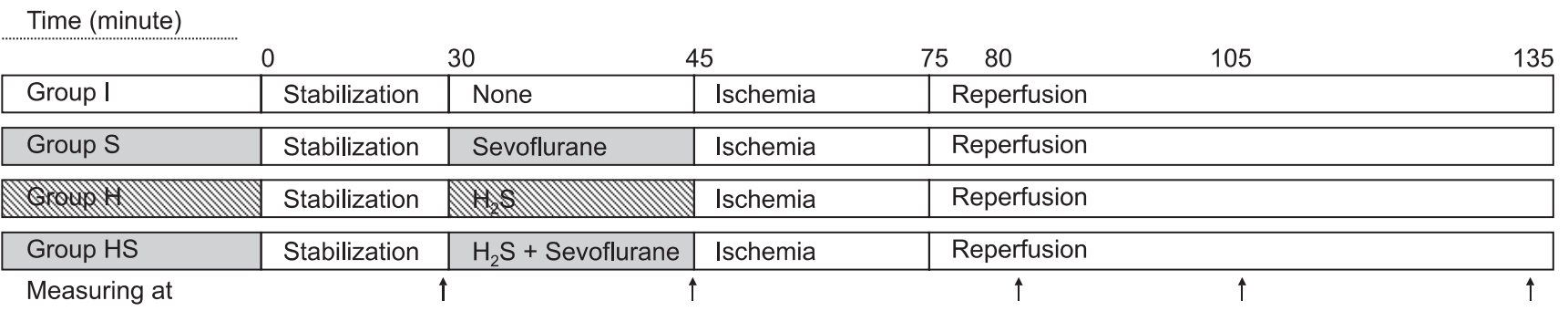

Fig. 1. Experimental protocol. After stabilization, each group was subjected to 30 minutes of global ischemia and 60 minutes of reperfusion. Before global ischemia, a 15 minute pre-treatment period was conducted and specific agents were applied to each group as follows: perfusate and mixed gas $\left(95 \% \mathrm{O}_{2}+5 \% \mathrm{CO}_{2}\right)$ only for group I; mixed gas with $1.6 \%$ sevoflurane and perfusate without $\mathrm{H}_{2} \mathrm{~S}$ for group S; $18.5 \mu \mathrm{M} \mathrm{H}_{2} \mathrm{~S}$ mixed perfusate and mixed gas for group $\mathrm{H} ; 1.6 \%$ sevoflurane and $18.5 \mu \mathrm{M} \mathrm{H}_{2} \mathrm{~S}$ for group HS. Hemodyamic variables were measured after stabilization, after pre-treatment and 5, 30,60 minutes after reperfusion started (Arrows). After all processes were completed, triphenyl tetrazolium staining was performed to calculate infarct size.

effluent flow rate (CEFR).

After reperfusion was completed, the heart was immediately frozen at $-20^{\circ} \mathrm{C}$ to prevent damage to the muscles. All of the ventricular muscles were cut into $2 \mathrm{~mm}$ along the short axis of heart, and the slices were stained with triphenyl tetrazolium in a water bath of $37^{\circ} \mathrm{C}$ for $10-15$ minutes. The staining agent was created by dissolving triphenyl tetrazolium salt (2,3,5-Triphenyl tetrazolium chloride: $\mathrm{C} 19 \mathrm{H} 15 \mathrm{CIN} 4)$ to $1 \%$ in a buffer solution of monosodium phosphate $\left(\mathrm{NaH}_{2} \mathrm{PO}_{4}\right)$ and disodium phosphate $\left(\mathrm{Na}_{2} \mathrm{HPO}_{4}\right)$ with a $\mathrm{pH}$ of 7.4 . Once staining was complete, each muscle segment was fixed for 20 minutes in a 10\% formaldehyde solution. The samples were then made into a uniform thickness with 2 thick glasses and $2 \mathrm{~mm}$ thick shims, then examined using a UTHSCSA Image Tool, version 3.0 (S. Brent Dove, University of Texas Health Science Center in San Antonio, Texas, USA). The volumes corresponded to the damaged tissues and all of the ventricles were measured and the infarct size was calculated as a ratio (\%) of the sum of damaged volumes to whole ventricle.

All statistical analyses were performed using SigmaStat for Windows, version 3.0.1a (Systat software Inc., San Jose, CA, USA). Friedman repeated measures analysis of variance on ranks or Kruskal-Wallis one-way analysis of variance on ranks was used, depending on the nature of the data. When the results were significant, multiple comparisons were made with the Dunn's Method. A P value of less than 0.05 was considered statistically significant.

\section{Results}

52 rat hearts were extracted and randomly divided into 4 groups. Rats in which technical failures occurred or adequate heart function did not continue through to stabilization were excluded. In total, group I contained 10 hearts, group S contained 13, group H contained 10, and group HS contained 12.

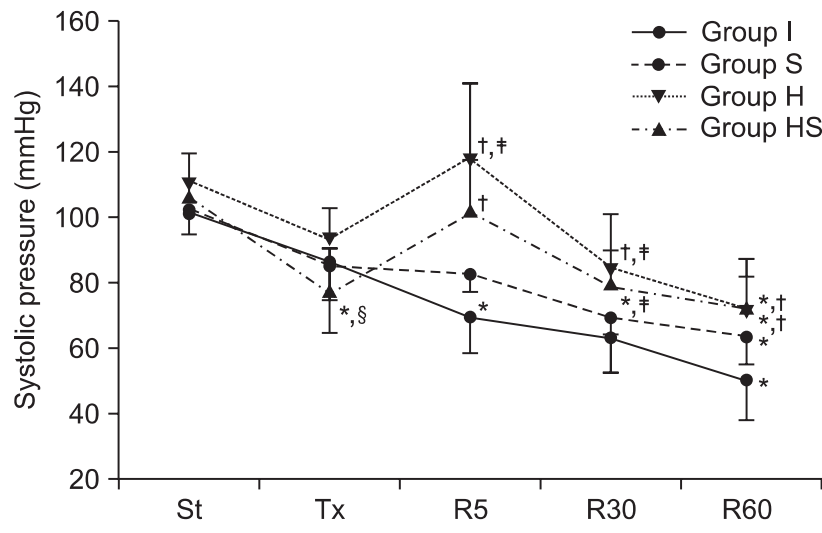

Fig. 2. Left ventricular end systolic pressure. Group HS showed lower systolic pressure after pre-treatment than those after stabilization. Groups $\mathrm{H}$ and HS showed mostly higher pressures during the reperfusion period than groups I and S. St: after stabilization, Tx: pretreatment, R5: reperfusion 5 minutes, R30: reperfusion 30 minutes, R60: reperfusion 60 minutes. $\mathrm{P}<0.05$ is remarked as follows: * vs. after stabilization in the same group. ${ }^{\dagger}$ vs. Group I, ${ }^{\dagger}$ vs. Group S, ${ }^{\S}$ vs. Group H at the same measurement time.

\section{Hemodynamic variables and CEFR}

In group HS, LVESP was lower immediately after pretreatment than after stabilization ( $\mathrm{P}<0.001$, Fig. 2 ). 5 minutes after reperfusion, LVESP was higher in group $\mathrm{H}$ than in groups I and $\mathrm{S}(\mathrm{P}<0.001)$. In group HS, the pressure was lower than in group $\mathrm{H}$, but did not show depressed LVESP as in group S. During the remainder of the reperfusion period, the pressure decreased gradually over time. However, the pressure was higher in groups $\mathrm{H}$ and $\mathrm{HS}$ than in group $\mathrm{I}(\mathrm{P}<0.001)$.

During the reperfusion period, LVEDP increased initially, then decreased gradually in all groups (Fig. 3). But 30 minutes after reperfusion, the pressure was lower in group $\mathrm{S}$ than in groups I and $\mathrm{H}(\mathrm{P}<0.001)$. Then, 60 minutes after reperfusion, the pressure was further decreased, and the differences bet- 


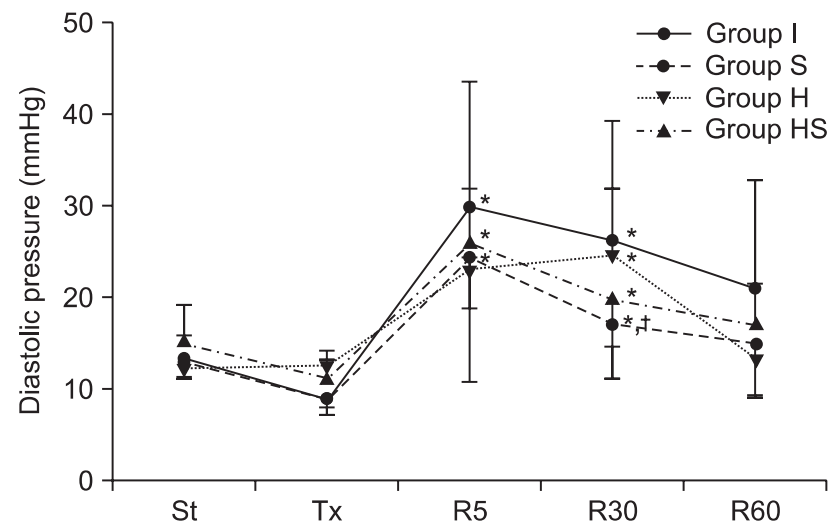

Fig. 3. Left ventricular diastolic pressure. During the reperfusion period, diastolic pressure in all groups initially increased, and then progressively decreased over time. In group $\mathrm{H}$, diastolic pressure was sustained at a high rate until 30 minutes after reperfusion and then decreased toward the value of that after stabilization. Groups $\mathrm{S}$ and HS showed similar patterns in pressure changes. St: after stabilization, Tx: pretreatment, R5: reperfusion 5 minutes, R30: reperfusion 30 minutes, R60: reperfusion 60 minutes. $\mathrm{P}<0.05$ is remarked as follows: * vs. after stabilization and/or pretreatment in the same group, ${ }^{\dagger}$ vs. groups I and $\mathrm{H}$ at the same measurement time.

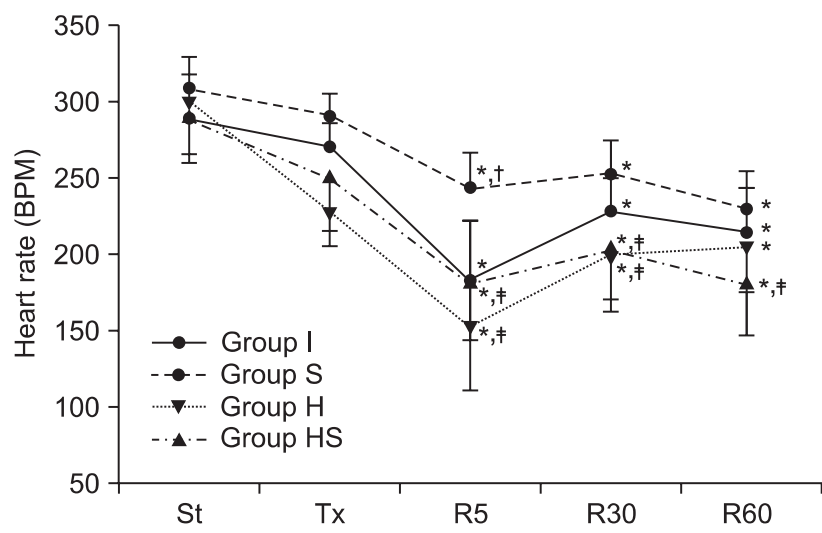

Fig. 4. Heart rate. Heart rates during the reperfusion period in all groups were lower than those prior to ischemia. Heart rates in groups $\mathrm{H}$ and $\mathrm{HS}$ were mostly lower than those in group $\mathrm{S}$ during the reperfusion period. St: after stabilization, Tx : pretreatment, R5: reperfusion 5 minutes, R30: reperfusion 30 minutes, R60: reperfusion 60 minutes. $\mathrm{P}<0.05$ is remarked as follows: * vs. after stabilization in the same group, ${ }^{\dagger}$ vs. groups $\mathrm{I},{ }^{\dagger}$ vs. group $\mathrm{S}$ at the same measurement time.

ween the groups disappeared.

All groups showed reduced HR during the reperfusion period. However, the rate was relatively higher in group $S$ than in groups $\mathrm{H}$ and $\mathrm{HS}(\mathrm{P}<0.001$, Fig. 4$)$.

$\mathrm{dP} / \mathrm{dtmax}$ in group $\mathrm{S}$ abruptly decreased 5 minutes after reperfusion, similarly to group I ( $<<0.001$, Fig. 5$)$. The decrement of $\mathrm{dP} / \mathrm{dtmax}$ was also observed in groups $\mathrm{H}$ and $\mathrm{HS}$, and group $\mathrm{S}$ showed a significantly greater drop than other groups. 30 and 60 minutes after reperfusion, $\mathrm{dP} / \mathrm{dtmax}$ in all groups

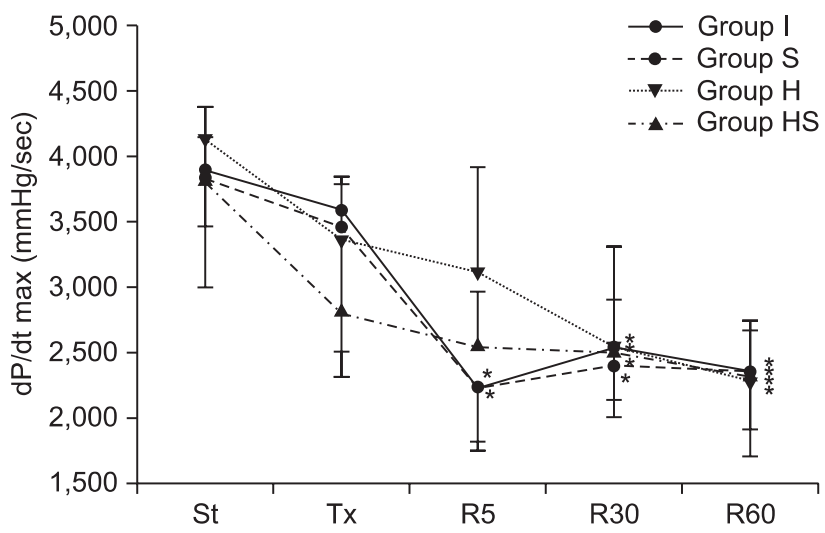

Fig. 5. Maximum rate of change of left ventricular pressure (dP/ $\mathrm{dt}$ max). 5 minutes after reperfusion, $\mathrm{dP} / \mathrm{dt}$ max in groups $\mathrm{I}$ and $\mathrm{S}$ decreased rapidly. During the rest of reperfusion, $\mathrm{dP} / \mathrm{dt}$ max of all groups remained low. St: after stabilization, Tx: pretreatment, R5: reperfusion 5 minutes, R30: reperfusion 30 minutes, R60: reperfusion 60 minutes. $\mathrm{P}<0.05$ is remarked as follows: * vs. after stabilization in the same group.

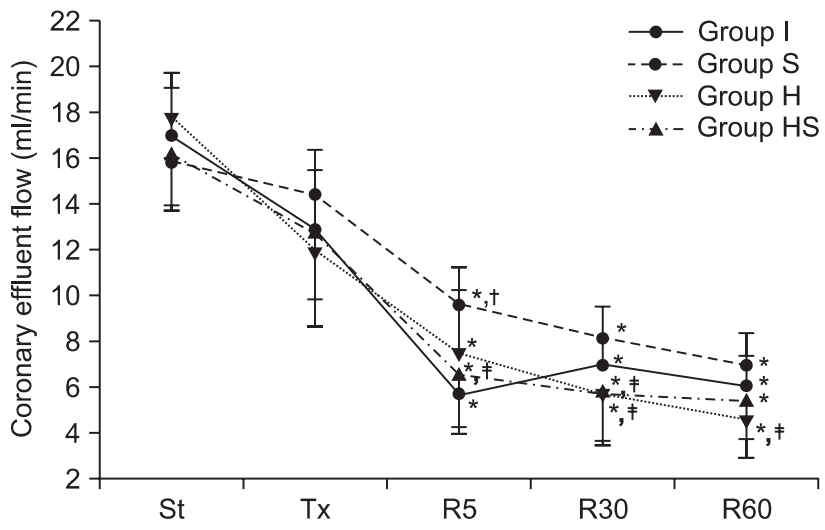

Fig. 6. Coronoary effluent flows measured in rate. During the reperfusion period, coronary effluent flow rates of all groups decreased with time. Primarily, group S showed higher rates than groups I, H and HS. St: after stabilization, Tx: pretreatment, R5: reperfusion 5 minutes, R30: reperfusion 30 minutes, R60: reperfusion 60 minutes. $\mathrm{P}<0.05$ is remarked as follows: * vs. after stabilization in the same group. At the same measuring time, ${ }^{\dagger}$ vs. groups $\mathrm{I},{ }^{\ddagger}$ vs. group $\mathrm{S}$ at the same measurement time.

maintained a lowered value compared to the values measured after stabilization. In all groups, CEFR showed a gradual reduction during the reperfusion period (Fig. 6). However, in group $\mathrm{S}$, the rate was generally higher than in the other groups throughout the reperfusion period $(\mathrm{P}<0.001)$.

\section{Infarct Size (Fig. 7)}

Infarct size was significantly smaller in groups $\mathrm{S}, \mathrm{H}$ and $\mathrm{HS}$ than in group I $(\mathrm{P}=0.001)$. There were no significant differences between groups $\mathrm{S}, \mathrm{H}$ and $\mathrm{HS}$. 


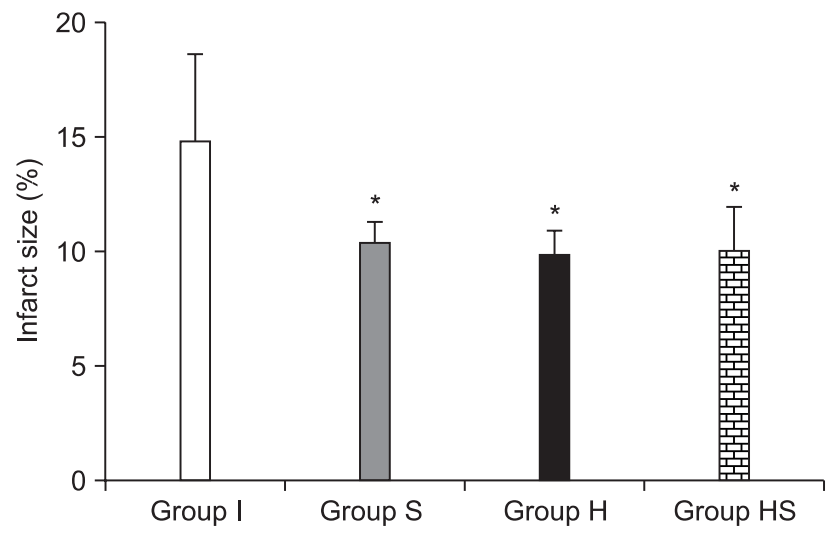

Fig. 7. Infarct size measured in each group. Groups S, H and HS showed smaller infarct size than group I. There was no difference between infarct size of groups $\mathrm{S}, \mathrm{H}$ and HS. P $<0.05$ is remarked as follows: * vs. group I.

\section{Discussion}

After ischemic preconditioning was introduced to prevent damage due to myocardial ischemia and reperfusion that occurs because of surgical manipulation or other causes [17], considerable research has been actively pursued and many clinical trials for the use of ischemic preconditioning are being performed [2]. Because pretreatment by short and repeated ischemia and reperfusion is highly dangerous [1], recent studies have focused on chemical pretreatments, including halogenated inhalation anesthetics and adenosine $[3,4]$. Among these agents, pharmacological preconditioning by inhalation anesthetics is mainly mediated through activation of protein kinase C (PKC) and ATP-sensitive potassium channels [18]. In addition, it has been demonstrated that inhalation anesthetics control the activity of nitric oxide synthase (NOS), which plays an important role in reducing ischemic damage and in maintaining CEFR [19]. Sevoflurane is a newly synthesized halogenated inhalation anesthetic and its pharmacological preconditioning effect is well known $[20,21]$.

Our study utilized 1.6 vol\% sevoflurane, which is significantly less than the $2.4 \%$, and this corresponds to $1 \mathrm{MAC}$ in rats. In our previous study, it was found that a 1.6 vol\% sevoflurane, which is short of $1 \mathrm{MAC}$, had a protective effect, where a concentration higher than 1.6 vol\% showed the same protective effect and instead reduced myocardial function [22]. Therefore, we chose to use 1.6 vol\% sevoflurane concentration in order to prevent myocardial depression induced by sevoflurane and we found that the sevoflurane-pretreated hearts had less reduced function than group I. In addition, hearts treated with 1.6 vol\% sevoflurane before ischemia had smaller infarct size compared to those in group I and so proved to have a pharmacological pretreatment effect. From a hemodynamic perspective, hearts that had been treated with sevoflurane showed a lower LVEDP, a higher HR and a higher CEFR during reperfusion than those in group I. These findings support the pharmacologic preconditioning effect of sevoflurane, as previously reported $[20,21]$.

$\mathrm{H}_{2} \mathrm{~S}$ is known to be involved in the regulation of the cardiovascular system and is accepted as a gasotransmitter, similar to $\mathrm{NO}$ and $\mathrm{CO}[5] . \mathrm{H}_{2} \mathrm{~S}$ was once thought to be toxic, but studies in mammals and human subjects have revealed that it is naturally produced in small amounts in the cardiovascular system. Since then, many studies have been focused on its function. In the cardiovascular system, $\mathrm{H}_{2} \mathrm{~S}$ primarily functions to activate ATP-sensitive potassium channels, dilating blood vessels [6]. $\mathrm{H}_{2} \mathrm{~S}$ has also been shown to suppress cytochrome c oxidase, which acts on the electron transfer system involved in cellular respiration. Thus, the suppression of oxidative phosphorylation results in extreme reduction of metabolism [13]. Moreover, externally administered $\mathrm{H}_{2} \mathrm{~S}$ has an effect similar to ischemic preconditioning in reducing damage to the myocardium from ischemia and reperfusion and also in reducing infarct size. ATP-sensitive potassium channel activation appears to have some relevant effects $[9,10]$. Also, a previous study in rat cardiomyocytes has shown that $\mathrm{H}_{2} \mathrm{~S}$ exerts a protective effect against ischemia through activation of $\mathrm{PKC}$, including translocation of $\mathrm{PKC} \alpha$ as well as $\mathrm{PKC} \varepsilon$, and $\mathrm{PKC} \delta$, which appears in the process of ischemic preconditioning, is slightly different in terms of PKC subtype. However, the relationships between $\mathrm{H}_{2} \mathrm{~S}$ and PKC are not yet clear [11,23-25]. $\mathrm{H}_{2} \mathrm{~S}$ is also believed to act as a buffer to increased oxygen consumption by regulating oxygen-consuming enzymes. In a study with mice, $150 \mathrm{ppm}_{2} \mathrm{~S}$ gas suppressed metabolic rate by up to $90 \%$, protecting mice from lethal hypoxia, suggesting that in hypoxia, $\mathrm{H}_{2} \mathrm{~S}$ can reduce the damage to myocardial tissue [14]. Beauchamp et al. [26] have reported that high concentrations of $\mathrm{H}_{2} \mathrm{~S}$ are toxic and can cause respiratory failure and pulmonary edema because it suppresses cytochrome c oxidase, disabling mitochondrial electron transport systems. It has been suggested that, through the same mechanism, low concentrations of $\mathrm{H}_{2} \mathrm{~S}$ can induce reversible suspended animation-like states in mammals $[13,14]$. Low concentrations of $\mathrm{H}_{2} \mathrm{~S}$, in the process of metabolizing oxygen to energy in cells, lowers the oxygen demand of cytochrome c oxidase, which in turn leads to the creation of fewer reactive oxygen species (ROSs) due to sudden oxygen cutoff or hypoxia and prevents ROS-related damage to cells during ischemia [14].

The physiological concentrations of $\mathrm{H}_{2} \mathrm{~S}$ in rats have been reported to vary between 10 and $50 \mu \mathrm{M}$, and the maximum value has been shown to be $45.6 \pm 14.2 \mu \mathrm{M}$ [6]. The concentration we used was $100 \mu \mathrm{M}$ NaHS which corresponds to 18.5 $\mu \mathrm{M} \mathrm{H}_{2} \mathrm{~S}$. This concentration was within physiological ranges and 
was not enough to affect the $\mathrm{pH}$ of the perfusate [27], and was a concentration used in previous studies $[7,8,11]$.

We administered $18.5 \mu \mathrm{M} \mathrm{H}_{2} \mathrm{~S}$ for 15 minutes prior to ischemia and found that it has a myocardial protective effect similar to sevoflurane; the infarct size in group $\mathrm{H}$ significantly reduced compared with group I. The reduction of infarct size was similar between the $\mathrm{H}_{2} \mathrm{~S}$ and sevoflurane pretreatment. LVESP was higher in group $\mathrm{H}$ than in group I, HR was lower in group $\mathrm{H}$ than in group $\mathrm{S}$, but $\mathrm{dP} / \mathrm{dt}_{\max }$ progressively decreased in later reperfusion periods. As in previous studies $[9,10], \mathrm{H}_{2} \mathrm{~S}$ produced myocardial protective effects against ischemia and reperfusion injury in terms of hemodynamic aspects as well as reduced infarct size.

Our study sought to elucidate the cardioprotection of a combined treatment of inhalation anesthetics with known pharmacological preconditioning activity, and $\mathrm{H}_{2} \mathrm{~S}$ which protects against myocardial ischemia and reperfusion. In the case of $\mathrm{H}_{2} \mathrm{~S}$, a mechanism similar to PKC translocation and ATP-sensitive potassium channel activation induced by inhalation anesthetics has been suggested. However, $\mathrm{H}_{2} \mathrm{~S}$ induces the translocation of different PKC subtypes [11] and suppresses cytochrome c oxidase, which will lead to the suspended animationlike phenomenon which indicates a status of extremely low metabolic rate followed by a reduction in core body temperature $[13,14]$. Moreover, some studies cast doubt on $\mathrm{H}_{2} \mathrm{~S}$ involvement in PKC translocation [25]. For these reasons, we expected good outcomes from the combined treatment with the inhalation anesthetic and $\mathrm{H}_{2} \mathrm{~S}$-induced suspended animation-like state. However, while the combined treatment reduced ischemia size, the results did not differ from those when each agent was used alone. Moreover, the combined treatment caused profound functional depression and showed no further hemodynamic benefits even though we used the minimum cardioprotective dose of each agent. In CEFR, although sevoflurane alone maintained a higher flow rate, the addition of $\mathrm{H}_{2} \mathrm{~S}$ caused the rate to drop to group I levels. Generally, volatile anesthetics vasodilate coronary arteries by activation of endothelium $\mathrm{K}_{\text {АTP }}$ channels and promote endothelial NO release [18]. Also, $\mathrm{H}_{2} \mathrm{~S}$ has a vasodilation effect; this effect is not related to $\mathrm{K}_{\mathrm{ATP}}$ channels activation, and the endogenous production of NO inhibits the vasodilatory effect of $\mathrm{H}_{2} \mathrm{~S}$ in coronary arteries [28]. Concerning CEFR, Geng et al. [15] reported that the effect of CEFR of $\mathrm{H}_{2} \mathrm{~S}$ is dependent on the concentration of $\mathrm{H}_{2} \mathrm{~S}$. NaHS in a concentration of $100 \mu \mathrm{M}$ did not affect the CEFR, but a higher concentration of NaHS inhibited CEFR in addition to a severe negative inotropic effect. These findings suggest that combined treatment with inhalation anesthetic and $\mathrm{H}_{2} \mathrm{~S}$ could have an adverse effect on CEFR and our experimental results support this effect.

However, it cannot be assumed that this completely rules out any possible additional benefits from the combined treatment. First, further studies are needed to ascertain whether $\mathrm{H}_{2} \mathrm{~S}$ induced metabolic suppression leads to temporary myocardial dysfunction. In order to determine this, we should examine metabolism in the control myocardium, each agent separately, as well as in combined treatment. Additionally, in in vivo experiments, we should look for early preconditioning effects after 60 minutes of reperfusion and late preconditioning effects 2-3 days after ischemia. In our research, combined treatment with sevoflurane and $\mathrm{H}_{2} \mathrm{~S}$ led to no additional benefit compared to a single treatment with sevoflurane or $\mathrm{H}_{2} \mathrm{~S}$ as an early preconditioning effect. Second, there is a possibility that a rate-limiting factor and a ceiling effect of cardioprotection exists in pharmacological preconditioning. Sevofluraneinduced cardioprotection against ischemia and reperfusion continues to increase as concentrations increase, but only up to $1.6 \%$ [22]. NaHS administered between the preischemic state and late reperfusion state in doses of $0.1 \mu \mathrm{M}$ and $1 \mu \mathrm{M}$ showed a progressive decrease in ischemia size, but at $10 \mu \mathrm{M}$ this effect did not occur [9]. Based on these results, including those of our study, more research is needed to determine what happens in the interaction between sevoflurane and naturally occurring $\mathrm{H}_{2} \mathrm{~S}$, considering its role as a gasotransmitter and a pharmacological preconditioner that reduces ischemia size.

In conclusion, we observed that $\mathrm{H}_{2} \mathrm{~S}$ administered to isolated rat hearts had preconditioning effects against ischemia and reperfusion injury, such as faster systolic pressure recovery and reduction of infarct size. Sevoflurane was found to have preconditioning effects, as reported previously. Combination treatment with $\mathrm{H}_{2} \mathrm{~S}$ and sevoflurane has an effect on infarct size reduction but caused a greater loss of hemodynamic function than a single treatment with $\mathrm{H}_{2} \mathrm{~S}$ or sevoflurane for each substance.

\section{References}

1. Vaage J, Jensen U, Ericsson A. Neurologic injury in cardiac surgery: aortic atherosclerosis emerges as the single most important risk factor. Scand Cardiovasc J 2000; 34: 550-7.

2. Valen G, Vaage J. Pre- and postconditioning during cardiac surgery. Basic Res Cardiol 2005; 100: 179-86.

3. Venugopal V, Ludman A, Yellon DM, Hausenloy DJ. 'Conditioning' the heart during surgery. Eur J Cardiothorac Surg 2009; 35: 977-87.

4. Weber NC, SchlackW. Inhalational anaesthetics and cardioprotection. Handb Exp Pharmacol 2008; 182: 187-207.

5. Wang R. Two's company, three's a crowd: can $\mathrm{H}_{2} \mathrm{~S}$ be the third endogenous gaseous transmitter? FASEB J 2002; 16: 1792-8.

6. Zhao W, Zhang J, Lu Y, Wang R. The vasorelaxant effect of $\mathrm{H}(2) \mathrm{S}$ as a novel endogenous gaseous K(ATP) channel opener. EMBO J 2001; 20: 6008-16.

7. Hu Y, Chen X, Pan TT, Neo KL, Lee SW, Khin ES, et al. Cardioprotection induced by hydrogen sulfide preconditioning involves 
activation of ERK and PI3K/Akt pathways. Pflugers Arch 2008; 455: 607-16.

8. Yong QC, Lee SW, Foo CS, Neo KL, Chen X, Bian JS. Endogenous hydrogen sulphide mediates the cardioprotection induced by ischemic postconditioning. Am J Physiol Heart Circ Physiol 2008; 295: H1330-40.

9. Johansen D, Ytrehus K, Baxter GF. Exogenous hydrogen sulfide $\left(\mathrm{H}_{2} \mathrm{~S}\right)$ protects against regional myocardial ischemia-reperfusion injury-Evidence for a role of $\mathrm{K}_{\mathrm{ATP}}$ channels. Basic Res Cardiol 2006; 101: 5360.

10. Ji Y, Pang QF, Xu G, Wang L, Wang JK, Zeng YM. Exogenous hydrogen sulfide postconditioning protects isolated rat hearts against ischemia-reperfusion injury. Eur J Pharmacol 2008; 587: 1-7.

11. Pan TT, Neo KL, Hu LF, Yong QC, Bian JS. $\mathrm{H}_{2} \mathrm{~S}$ preconditioninginduced PKC activation regulates intracellular calcium handling in rat cardiomyocytes. Am J Physiol Cell Physiol 2008; 294: C169-77.

12. Bian JS, Yong QC, Pan TT, Feng ZN, Ali MY, Zhou S, et al. Role of hydrogen sulfide in the cardioprotection caused by ischemic preconditioning in the rat heart and cardiac myocytes. J Pharmacol Exp Ther 2006; 316: 670-8.

13. Blackstone E, Morrison $\mathrm{M}$, Roth $\mathrm{MB} . \mathrm{H}_{2} \mathrm{~S}$ induces a suspended animation-like state in mice. Science 2005; 308: 518.

14. Blackstone E, Roth MB. Suspended animation-like state protects mice from lethal hypoxia. Shock 2007; 27: 370-2.

15. Geng B, Yang J, Qi Y, Zhao J, Pang Y, Du J, et al. $\mathrm{H}_{2} \mathrm{~S}$ generated by heart in rat and its effects on cardiac function. Biochem Biophys Res Commun 2004; 313: 362-8.

16. Li J, Zhang G, Cai S, Redington AN. Effect of inhaled hydrogen sulfide on metabolic responses in anesthetized, paralyzed and mechanically ventilated piglets. Pediatr Crit Care Med 2008; 9: 1102.

17. Murry CE, Jennings RB, Reimer KA. Preconditioning with ischemia: a delay of lethal cell injury in ischemic myocardium. Circulation 1986; 74: 1124-36.

18. Zaugg M, Lucchinetti E, Uecker M, Pasch T, Schaub MC. Anaesthetics and cardiac preconditioning. Part I. Signalling and cytoprotective mechanisms. Br J Anaesth 2003; 91: 551-65.

19. Novalija E, Fujita S, Kampine JP, Stowe DF. Sevoflurane mimics ischemic preconditioning effects on coronary flow and nitric oxide release in isolated hearts. Anesthesiology 1999; 91: 701-12.

20. Oguchi T, Kashimoto S, Yamaguchi T, Masui K, Kumazawa T. Sevoflurane reduces dysrhythmias during reperfusion in the working rat heart. J Anesth 2001; 15: 22-8.

21. Piriou V, Chiari P, Lhuillier F, Bastien O, Loufoua J, Raisky O, et al. Pharmacological preconditioning: comparison of desflurane, sevoflurane, isoflurane and halothane in rabbit myocardium. Br J Anaesth 2002; 89: 486-91.

22. Lee MK, Lee DK, Kim NS, Kong MH, Lee IO, Oh HR, et al. Comparisons of myocardial protective effects of sevoflurane at different concentrations against ischemia in isolated rat heart. Korean J Anesthesiol 2004; 47: 246-52.

23. Uecker M, Da Silva R, Grampp T, Pasch T, Schaub MC, Zaugg M. Translocation of protein kinase $\mathrm{C}$ isoforms to subcellular targets in ischemic and anesthetic preconditioning. Anesthesiology 2003; 99: 138-47.

24. Wang Y, Hirai K, Ashraf M. Activation of mitochondrial ATPsensitive $\mathrm{K}^{+}$channel for cardiac protection against ischemic injury is dependent on protein kinase C activity. Circ Res 1999; 85: 731-41.

25. Bliksoen M, Kaljusto ML, Vaage J, Stenslokken KO. Effects of hydrogen sulphide on ischaemia-reperfusion injury and ischaemic preconditioning in the isolated, perfused rat heart. Eur J Cardiothorac Surg 2008; 34: 344-9.

26. Beauchamp RO Jr, Bus JS, Popp JA, Boreiko CJ, Andjelkovich DA. A critical review of the literature on hydrogen sulfide toxicity. Crit Rev Toxicol 1984; 13: 25-97.

27. Dombkowski RA, Russell MJ, Schulman AA, Doellman MM, Olson KR. Vertebrate phylogeny of hydrogen sulfide vasoactivity. Am J Physiol Regul Integr Comp Physiol 2005; 288: R243-52.

28. Hussain A, Maddock H, Al-Rajaibi H, Carson RJ. Effects of hydrogen sulphide on the isolated perfused rat heart. Sultan Qaboos Univ Med J 2011; 11: 236-44. 